\title{
Conferência
}

\section{O desafio da solidariedade e do amor na pós-modernidade}

\section{The challenge of solidarity and love in postmodernity}

Jocinei Godói Lima1

0000-0002-0569-8036

\begin{abstract}
Resumo
O presente artigo objetiva falar sobre a solidariedade e o amor frente ao desafio de atuar sob esse tema na pós-modernidade. O atual período tem sido identificado, conforme propôs Jean-François Lyotard (1924-1998), como aquele em que as grandes narrativas que conduziam o imaginário humano têm perdido a sua força em razão da incredulidade característica deste tempo. Assim, surge um problema, a ser tratado neste trabalho, que reside na busca pela melhor forma de atuar num tempo de ceticismos, confusões e incertezas epistemológicas, tendo como base os preceitos e orientações decorrentes de conceitos como solidariedade e amor, tão caros e eivados de pressupostos teológicos, sobretudo cristãos. O problema aqui proposto não se refere ao cristianismo em si, mas à dificuldade para tomar conceitos notadamente cristãos diante de um tempo de recusa ao uso de pressupostos que façam parte de estruturas tradicionais. Para lançar luz a esse problema serão utilizadas, pelo menos, duas fontes de saber. A primeira diz respeito ao conteúdo apresentado pelo Monsenhor Bruno-Marie Duffé (Secretário do Dicastério para o Desenvolvimento Humano Integral - Vaticano) na PUC-Campinas em 2019. A segunda refere-se aos textos do sacerdote e teólogo católico checo Tomáš Halík (1948-), que remetem à esperança como a chave para atuar de modo concreto levando em consideração os aspectos de solidariedade e amor. A partir do percurso firmado para a investigação do problema, postula-se a hipótese de que tanto a apresentação do Monsenhor Bruno-Marie Duffé como o tema da esperança colocado por Halík constituem-se um poderoso instrumento para que o diálogo e as ações de ordem prática aconteçam de um modo em que a dignidade humana esteja sempre em pauta, resultando em ações de solidariedade e de amor mesmo neste tempo de mais dúvidas do que de certezas. Assim, a conclusão deste trabalho remete à ideia de que as ações de solidariedade e de amor, realizadas sob a chave da esperança cristã, podem ser uma saída plausível para que, independente das crenças assumidas, tenham um efeito benéfico nas diversas relações na pós-modernidade.
\end{abstract}

Palavras-chave: Amor. Esperança. Pós-modernidade. Solidariedade.

\begin{abstract}
This article aims to discuss solidarity and love in the face of the challenge of acting on this theme in post-modernity. The current period has been identified, as proposed by Jean-François Lyotard (1924-1998), as the one in which the great narratives that guided the human imagination have lost their strength due to the disbelief characteristic of this time. Thus, a problem to be addressed in this work comes up, which lies in the search for the best way to act in a time of

\footnotetext{
1 Pontifícia Universidade Católica de Campinas, Centro de Ciências Humanas e Sociais Aplicadas, Programa de Pós-Graduação em Ciências da Religião. R. Prof. Dr. Euryclides de Jesus Zerbini, 1516, Parque Rural Fazenda Santa Cândida, 13087-571, Campinas, SP, Brasil. E-mail: joci.godoy@gmail.com

Apoio: Coordenação de Aperfeiçoamento de Pessoal de Nível Superior.
} 
skepticism, confusion and epistemological uncertainties, based on the precepts and guidelines arising from concepts such as solidarity and love that are so dear and fraught with theological assumptions, above all, Christians. The problem proposed here does not refer to Christianity itself, but to the difficulty in taking notably Christian concepts in the face of a time of refusal to use presuppositions that are part of traditional structures. To shed light on this problem, at least two sources of knowledge will be used. The first concerns the content presented by Monsignor Bruno-Marie Duffé (Secretary of the Department for Integral Human Development - Vatican) at PUC-Campinas in 2019. The second refers to texts by Czech Catholic priest and theologian Tomáš Halík (1948-), which refer to hope as a key to acting concretely, taking into account the aspects of solidarity and love. From the path established for the investigation of the problem, the hypothesis is that both the presentation of Monsignor Bruno-Marie Duffé and the theme of hope raised by Halik constitute a powerful instrument for dialogue and practical actions to take place in a way that human dignity is always on the agenda, resulting in actions of solidarity and love even in this time of more doubts than certainties. Therefore, the conclusion of this work leads to the idea that actions of solidarity and love, carried out under the key of Christian hope, can be a plausible solution so that, regardless of the beliefs assumed, they bring a beneficial effect to the various relationships in the postmodernity.

Keywords: Love. Hope. Postmodernity. Solidarity.

\section{Introdução}

A atualidade tem sido marcada por intensos debates e acaloradas polarizações, especialmente no âmbito político. Isso por si só não se constitui um problema com desdobramentos negativos para a sociedade. Pelo contrário, os debates possuem em sua natureza o componente do contraditório, salutar para a construção do conhecimento sólido, livre de suposições vazias e assentadas em crenças que não se sustentam na realidade ordinária. Contudo, a situação tem fugido do controle e da sensatez nos últimos tempos, de forma que os debates têm alcançado a esfera da disputa pelo poder a qualquer custo e as polarizações têm se traduzido em sectarismos bastante perniciosos à sociedade de modo geral. Isso remete a um grave problema que afeta as várias camadas da sociedade, impossibilitando o diálogo e o consenso entre as pessoas.

O que se nota é que as formas de crença características das religiões, tradicionais ou não, cada vez mais têm sido trazidas para a esfera política, cujas ações e discursos de defesa daquilo que cada um possui como a "sua verdade" acabam por reduzir o debate à mera briga para provar a própria razão, independente da contribuição do outro para o diálogo que, na prática, não acontece. Em partes, esse é outro aspecto que tem marcado o presente tempo: o "sentimento de verdade". Em outras palavras, a ideia de que a verdade depende da interpretação de cada um e a sua própria subjetividade, mais no campo da emoção do que da própria razão, caracteriza esta era como a era da "pós-verdade". O agravo dessa situação reside na tentativa intencional de fornecer informações falsas com o objetivo de alcançar algum resultado positivo, pessoal ou coletivo, ao influenciar as massas com essa enganação.

Diante desse cenário, torna-se imperativo que ações sejam efetivamente tomadas em várias esferas da sociedade - política, econômica, cultural, religiosa etc. --, a fim de que a civilização atual não caia em abismos abertos por ela mesma. Nesse sentido, o desafio de atuar na sociedade, conforme a apresentação do Monsenhor Bruno-Marie Duffé na conferência proferida na PUC-Campinas em 2019 (DUFFÉ, 2019), em consonância com o tema da esperança proposto por Tomáš Halík (HALík, 2019), apresenta-se como alternativa plausível e viável para uma conversão, não no sentido teológico, mas de pura e simples mudança de rota; ou seja, de dar meia-volta e seguir o caminho da solidariedade e do amor sob a chave da esperança. Os tópicos a seguir 
procurarão desenvolver essas alternativas desembocando na conclusão de que, mais do que possível, é urgente que as sociedades de todo o mundo atuem sem a obrigatoriedade de levantar a bandeira cristã, mas de refletir e considerar alguns pressupostos cristãos importantes que, na prática, tendem a trazer muito mais benefícios de ordem relacional do que prejuízos de qualquer natureza.

\section{O período pós-moderno: vilão ou herói?}

O título desta seção parece um tanto intrigante. Ainda não há denominação definitiva acerca do período contemporâneo. Porém, é consenso entre os intelectuais acadêmicos que o atual período difere em alguns aspectos daquilo que ficou conhecido como modernidade. A fé que outrora - na Idade Média -, havia sido capitaneada pela tradição cristã, na modernidade foi direcionada sob a forma de crença na razão iluminista como aquela que traria o progresso e a paz. Ledo engano. O que se considerava esperança cristã transmutou-se em esperança terrena, dos próprios esforços humanos com vistas a atingir uma pacificação global. Como se sabe, o projeto de modernidade não obteve êxito nesse sentido, principalmente quando se observam os desdobramentos do século XX com suas guerras e genocídios. Sobre o tema da tomada da esperança como uma ilusão na modernidade, Tomáš Halík, escreveu:

Justamente por isso é importante cuidar e proteger a esperança como uma pequena chama em meio à tempestade, protegê-la da tentação da desesperança, mas ao mesmo tempo também de sua perdição e de sua deturpação, daquilo que seria um substituto falso: a ilusão, a projeção de nossos desejos, promessas utópicas ou um otimismo ingênuo, representado, por exemplo, pela ideologia moderna da promessa de um progresso irrestrito (HALíK, 2019, p. 9).

Mesmo com as guerras e catástrofes ocorridas, em grande parte em função do mau emprego da técnica, é evidente que o período moderno trouxe algo de muito positivo a partir do progresso científico e da desmistificação de várias práticas e saberes que antes eram entendidos sob a luz de uma tradição religiosa que não se sustentava na realidade. Um exemplo claro disso reside naquilo que ficou conhecido como "revolução copernicana"; isto é, a mudança da concepção do universo em que pese à forma de compreensão do sistema, saindo do modelo geocêntrico (Terra no centro) para o heliocêntrico (Sol no centro). Essa situação marcante tem sido considerada o início da Era Moderna.

Ao avançar para o presente tempo, a despeito da ideia de que não se pode defini-lo com exatidão, chega-se de forma aproximada e com certa apologia entre os intelectuais ao termo "pós-modernidade". É evidente que o termo não representa completamente todas as nuances da contemporaneidade, até porque ela ainda está em curso. O fato é que, neste artigo, a tomada desse termo diz respeito mais ao abandono de metarrelatos pretensamente portadores da solução das mazelas existenciais humanas do que exclusivamente a um movimento de total ruptura com a modernidade (LYOTARD, 2009). Isto posto, a perspectiva quanto às incertezas epistemológicas e, por extensão, a desconfiança a respeito das mais variadas instituições humanas, são marcas que diferenciam o homem moderno do homem contemporâneo. 
Diante disso, uma das hipóteses aventadas é que este período tem trazido à tona um pensamento de desesperança que se traduz em descrença de um mundo melhor. O medievo foi marcado pela fé canalizada e impulsionada pela tradição cristã. A modernidade canalizou sua esperança em uma razão com boas pretensões, porém com resultados lastimáveis do ponto de vista civilizacional. Já o presente período tem se demonstrado resistente a qualquer pretensão de progresso ou de ação, natural ou sobrenatural, que busque solução para os dilemas humanos. Não que o presente tempo seja um vilão, longe disso. Contudo, tem sido aparente o desafio de se propor algo racionalmente bem fundamentado frente à defesa do próprio ponto de vista, sob a chave do pathos ${ }^{2}$, uma vez que a humanidade parece encontrar dificuldade em apoiar-se em algum fundamento proposto seja pela religião, seja pela ciência.

\section{A solidariedade e o amor sob a ótica cristã: uma saída possível}

Como já observado, identificar o atual período como um vilão parece não ser uma saída adequada e não resolve os dilemas contemporâneos. Talvez alguém seja tentado a pensar que, como se vive na era do pós - pós-cristianismo; pós-modernidade; pós-verdade etc. -, dificilmente será possível encontrar alguma solução sólida frente à liquidez característica desse tempo, conforme descreveu o grande sociólogo polonês Zygmunt Bauman (1925-2017). Aqui se destaca, com a devida vênia, uma experiência pessoal neste exato momento e que, muito coincidentemente, exemplifica bem essa afirmação: enquanto escrevia este artigo, ao espiar uma página de filosofia em uma rede social, o autor acabou visualizando um meme com duas imagens: a primeira mostrava uma moça sendo entrevistada e dizendo que se apaixonou doze vezes em um ano e a segunda mostra o Bauman - referindo-se à entrevistada -, dizendo "nossa, que líquido". De forma imagética, isso representa bem a liquidez deste tempo.

Dito isso e retomando a conferência exposta pelo Monsenhor Duffé, mesmo a contragosto de muitos intelectuais ou não, a tradição cristã, quando assimilada de modo a não impor qualquer tipo de violência simbólica - em uma linguagem bourdiana -, ou seja, quando seu discurso atinge um âmbito libertador com vistas a fomentar a dignidade humana, tem-se aí uma possível solução para os atuais desafios, que vão desde as relações socioculturais mais básicas até as mais complexas. Se for possível falar em um projeto de vida pessoal e também comunitário, tendo o Cristo como um exemplo de perfeição, isso ocorre graças a uma hermenêutica que reconhece em Cristo algo que está para além dEle mesmo; isto é, algo que remete a Ele como uma divindade que se encontra em constante comunhão com o seu Pai.

Se ambos, Pai e Filho, "são" 3 Deus, pode-se dizer que as palavras de ambos são divinas. Nesse caso, Deus Pai, não somente a partir de Deus Filho, mas a partir de toda humanidade, confere a ela a possibilidade de ser "cocriadora" de Deus, em um gesto de transferência de dignidade do Criador para a sua criação. Neste ponto, cabe ressaltar a não necessidade de se tornar um cristão,

\footnotetext{
${ }^{2}$ Nesse caso, o termo pathos pode ser traduzido como paixão, cujo significado remonta à ideia kantiana de domínio total e profundo que um estado afetivo exerce sobre toda a personalidade (ou "subjetividade") do indivíduo (ABBAGNANO, 2007).

3 A palavra "são" entre aspas sugere o erro consciente dessa forma verbal em razão da dificuldade de designação das pessoas da Trindade cristã, neste caso, duas delas: Pai e Filho.
} 
praticante ou não, para admitir os aspectos inerentes à dignidade da pessoa humana, cujas raízes remontam à tradição cristã. Quando se recorre, por exemplo, ao extenso e frutífero tratado ético feito por Cristo naquele que ficou conhecido como "o sermão da montanha" ${ }^{4}$ é inegável que algum aprendizado seja obtido baseado nos aspectos de solidariedade e do amor, temas centrais do evangelho e sempre presentes nas palavras de Cristo.

A contemplação característica de Cristo frente ao Pai e a atenção dAquele para com o próximo demonstram que é possível viver uma vida de devoção à Deus, que se traduz no cuidado com as pessoas que se apresentam pelo caminho. Cristo amava cuidando e escutando as pessoas. Sua sensibilidade frente ao sofrimento alheio era algo que o constituía ontologicamente. Assim como Cristo recebia algo dos seus companheiros, Ele também agia com doação na mesma medida ou até em demasia. Essa é uma importante lição a ser aprendida com o Mestre. Aprender a receber para aprender a dar de modo solidário e amoroso. Essas ações podem ser assumidas em vários âmbitos da sociedade, sobretudo no âmbito político. O ambiente político pode ser um poderoso meio de se praticar ações de caridade exemplificadas no cuidado com o outro, tendo em vista a solidariedade em sua cabal forma de expressão.

Nisso, chega-se a um ponto de ligação da dimensão espiritual com a dimensão física: o aspecto político pode e deve ser praticado com o fim de atingir, de modo cuidadoso e justo, o bem comum. Através da espiritualidade cristã que visa a caridade, a política pode assumir um status de instrumento de graça e de benfeitoria à determinada comunidade. É um possível encontro do sobrenatural com o natural para os que creem. Se Deus, nas palavras de Cristo, quer o homem feliz consigo mesmo e com o outro, a política pode também ser um canal para que isso aconteça. Se os pressupostos de solidariedade e de amor fizerem parte das ações políticas, certamente os resultados serão os melhores possíveis.

Não somente quem pratica a política, mas quem recebe ou é impactado pelas suas ações, ao ter a mesma motivação assentada nesses pressupostos, dificilmente não agirá de forma benevolente com seu próximo. É uma teia em que todos estão ligados pela mesma motivação e propósito: ser solidário e amoroso para com o outro, uma vez que Cristo, enquanto paradigma existencial, agiu a esse respeito de modo eficaz e cabal em seu sofrimento e morte vicários. Eis uma saída plausível e viável para o atual momento de crise pandêmica e de desumanização que assola a sociedade.

\section{A esperança cristã como porta para o diálogo}

Na era da pós-verdade tem sido difícil o diálogo aberto que visa a construção de um conhecimento sólido, livre de paixões que residam na simples e pura defesa da própria opinião. Aqui, a palavra opinião não é utilizada de forma inconsciente, pelo contrário. Os amantes do saber sabem que essa palavra, cuja transliteração grega doxa, "[...] designa qualquer conhecimento (ou crença) que não inclua garantia alguma da própria validade" (ABBAGNANO, 2007, p. 729). Assim, a mera defesa da própria opinião, enquanto algo que supostamente pode ser invalidado frente à verdade, vem tomando conta dos debates neste tempo e resultando em ambientes de "cacofonia epistemológica".

${ }^{4} \mathrm{O}$ "sermão da montanha" pode ser encontrado, especialmente, nos capítulos 5, 6 e 7 do Evangelho segundo escreveu São Mateus na segunda parte da Bíblia Sagrada conhecida como Novo Testamento. 
Os fatos objetivos têm sido cada vez menos influentes na formação de conclusões pelas pessoas. A ideia nietzschiana de que "não existem fatos, apenas interpretações" tem sido utilizada de forma descabida, além de constituir-se como o mote da era pós-moderna. A solução para esse dilema aparentemente insolúvel mostra-se cada vez mais distante, como uma embarcação que se apequena no horizonte. Qualquer diálogo pode chegar ao fim ou nem mesmo começar adequadamente se alguém saca a sua própria verdade como uma arma letal que visa fulminar a ideia alheia. A verdade tornou-se propriedade de cada um, além de um passaporte pessoal que confere legitimidade e condições supostamente seguras para se chegar ao destino desejado. Vencer o debate é o que importa. O consenso e a construção de um conhecimento epistemologicamente válido podem esperar - ou nem mesmo são trazidos à tona. Nesse interim, a falta de consideração do ponto de vista do outro acaba por ser anulada, dando lugar ao desespero existencial de estar certo a qualquer custo.

O desfecho dessa situação parece ser o pior possível. Como se não bastasse a atual pandemia de COVID-19 ter tirado milhões de vidas pelo mundo todo, acabou também sendo politizada, tornando-se mero objeto de discussão sobre vacinação, possíveis formas de tratamento etc. Nesse contexto, haveria algo que pudesse remediar a atual conjuntura de dificuldade de consenso e prazer pelo dissenso? Felizmente a resposta é um altissonante sim. É evidente que, mesmo com uma sonora resposta positiva apontando a solução desse problema, as dificuldades de sua implementação se apresentam quase que na mesma proporção. Qual seria, então, o fator de remediação? A proposta para corroborar com essa afirmação reside na "esperança cristã".

Neste ponto, deve ficar claro mais uma vez que não se trata de firmar compromissos de ordem "religiosa-institucional" quando se fala da esperança cristã. Mais do que um "apelo proselitista", a esperança cristã, assim como exposto por Tomáš Halík na obra já mencionada, apresenta-se, ao mesmo tempo, como uma chave e porta para o diálogo construtivo e pacífico. Halík faz a seguinte indagação, que provoca o leitor a repensar os limites da vaidade humana na desconsideração de aspectos de ordem transcendentais que dizem respeito ao próprio mistério da sua existência: "O esforço de assumir o controle sobre o mistério da vida, sobre o mistério da existência humana não é, também, uma expressão da perda de esperança e confiança na realidade em si, em seu sentido não fundamentado pelo homem?" (HALíK, 2019, p. 51, grifos do autor).

O tempo despendido e as ações realizadas em diversas partes do mundo com o objetivo de alcançar a paz mundial têm sido traduzidos em tentativas frustradas. Qual seria a razão disso? Uma delas, talvez a principal, poderia residir no fato de a humanidade tentar encontrar em si mesma ou na esfera da imanência, apenas, o remédio que sararia a chaga da vaidade humana levada às últimas consequências. Tanto uma religiosidade mórbida como um apelo idolátrico à razão foram utilizados como recursos para levar a cabo projetos de pacificação global, porém todos sem sucesso. Aqui a esperança cristã se mostra como uma ferramenta indispensável para a busca por um mundo melhor. Não a esperança da barganha mesquinha com Deus, nem mesmo a esperança de se obter apenas conforto, como se o Criador devesse satisfações ou obrigações à sua criação. Mais do que isso, uma esperança que aponta para uma aurora de reconhecimento do outro como um semelhante, com ações recíprocas de caridade, cujo objetivo se assente na ideia de tornar este mundo melhor ou, para os que creem, de juntos se encontrarem em um mundo melhor. 
A esperança chamada de cristã pode e deve ser a esperança de todos, aberta ao diálogo e à aceitação mesmo daquele que não professa fazer parte de alguma instituição religiosa. Essa esperança, nas palavras de Halík:

[...] é, portanto, uma realidade divino-humana - de modo semelhante como o cristianismo reconhece em Jesus Cristo e na Igreja essa união de divino e humano; é justamente essa visão da esperança como um lugar do diálogo de Deus com os seres humanos que representa a contribuição especificamente cristã para a reflexão sobre a esperança (HALÍK, 2019, p. 62, grifos do autor).

Eis o caminho proposto por Halík e endossado neste tópico, que leva a uma possível saída, palpável e à vista de quem se dispõe a vê-la, para o diálogo profícuo que objetive a melhoria das relações humanas, resultando no bem-estar das comunidades afetadas pela disposição para o exercício da compaixão e do desapego à egolatria característica da pós-modernidade.

\section{Considerações Finais}

A pós-modernidade tem se apresentado como um período de marcantes desafios que dizem respeito à boa convivência humana. Se por um lado o ser humano melhorou no sentido de evitar, tanto quanto possível, guerras e catástrofes que marcaram os tempos passados, por outro lado ainda acontecem ações pontuais no globo terrestre de: terrorismos decorrentes de fundamentalismos religiosos; a disseminação, em escala planetária, de um vírus que resultou em pandemia; disseminação de "outro vírus" que diz respeito à propagação de notícias falsas com o objetivo de ludibriar as massas e manipular a tomada de decisões de ordem política que, na verdade, apresentam-se sob a forma de fake news; devastação da natureza para fins econômicos ilícitos; enfim, a lista é grande.

Tem-se a impressão de que apenas pelos esforços humanos, ainda que bem intencionados, a dificuldade para se chegar à paz global ou ao consenso entre as pessoas de determinada comunidade continua tão ou mais evidente do que em tempos passados. A descrença e o desencantamento do homem pós-moderno, seja com a religião tradicional ou com a ciência, apontam para um cenário caótico de difícil concatenação epistemológica e afetiva entre os indivíduos das sociedades em geral. Entretanto, há uma possível saída que remete ao conceito cristão de esperança, cujos efeitos práticos se traduzem em ações de solidariedade e de amor.

Paradoxalmente, esse conceito, bem como a sua prática, se constitui um belo e assombroso desafio. Belo porque remete ao melhor de cada indivíduo, que pode ser buscado através da contemplação cristã; ou seja, de buscar, ao mesmo tempo, fora e dentro de si aquilo ou Aquele que pode ajudar na busca por se tornar pessoas melhores. Assombroso por que isso requer não qualquer filiação religiosa tradicional ou institucional, mas uma espiritualidade para a qual se imagina não estar preparado; porém, no modo da esperança cristã, como bem apontou Halík: "[...] uma esperança que não se apoia nas coisas do mundo e não se agarra a elas, uma esperança que nos liberta da necessidade de nos agarrar a elas e que nos liberta da sua dependência" (HALIK, 2019, p, 175). Portanto, mesmo em um tempo de aparente dificuldade de aceitação do outro que pensa diferente, a partir da esperança cristã é possível viver na pós-modernidade, sob 
8 J.C. LIMA

o desafio da solidariedade e do amor - desafio que instiga e conduz docemente o ser humano na caminhada existencial, ainda que espinhosa e acidentada; porém, para os que creem, com a permanente presença e ajuda do Autor da vida. E isso basta.

\section{Referências}

ABBAGNANO, N. Dicionário de filosofia. 5. ed. São Paulo: Martins Fontes, 2007.

DUFFÉ, B.-M. O que quer dizer atuar no desafio da solidariedade e do amor? Campinas: PUC-Campinas, 2019. Publicado pelo canal da PUC-Campinas. Disponível em: https://www.youtube.com/watch?v=YYE2FXuttPg. Acesso em: 22 set. 2021

HALÍK, T. Não sem esperança: o retorno da religião em tempos pós-otimistas. Petrópolis: Vozes, 2019.

LYOTARD, J.-F. A condição pós-moderna. 12. ed. Rio de Janeiro: José Olympio, 2009.

Como citar este artigo/How to cite this article

LIMA, J. G. O desafio da solidariedade e do amor na pós-modernidade. Cadernos de Fé e Cultura, v. 6, e215511, 2021.

https://doi.org/10.24220/2525-9180v6e2021a5511 